\title{
Technical Note: Immunomagnetic Procedure for Positive Selection of Macrophages in Ovine Milk
}

\author{
M. Caroprese, ${ }^{1}$ A. Marzano, L. Schena, and A. Sevi \\ Dipartimento PRIME and Istituto per la Ricerca e le Applicazioni Biotecnologiche per la Sicurezza e la Valorizzazione \\ dei Prodotti Tipici e di Qualità (BIOAGROMED), Università di Foggia, Via Napoli 25, 71100 Foggia, Italy
}

\begin{abstract}
A simple immunomagnetic procedure was developed to select macrophages from ovine milk by using a nonspecific magnetic positive separation technique. Samples of ewe bulk milk were collected during early, mid, and late lactation; milk samples were centrifuged at $2,000 \times g$ for $30 \mathrm{~min}$ at $4^{\circ} \mathrm{C}$; the fatty fraction and supernatant were removed, and each pellet was dissolved in $500 \mu \mathrm{L}$ of $\mathrm{pH} 7.4$ phosphate buffered saline $+0.02 \% \mathrm{NaN}_{3}$. Cells were targeted for selection by using mouse-IgG anti-ovine macrophages. Several trials, testing 2 different fluorochrome-conjugated antibodies [i.e., mouse anti-human CD14:R-Phycoerythrin (RPE) (MCA1568PE, Serotec) and F(ab')2 rabbit anti-mouse IgG:RPE (STAR12A, Serotec)] and 3 different labeling procedures, were performed to evaluate the purity of samples by flow cytometry. A morphological test was carried out by direct microscopic count in enriched fraction smears stained with May-Grünwald-Giemsa stain to confirm the presence of macrophages. The method described in the present technical note can be considered an innovative application to obtain a single-cell population of high purity selected from all the somatic cells in milk.
\end{abstract}

Key words: macrophage, ovine milk, immunological selection

Milk quality and udder health are closely connected to the bacterial concentration and SCC of milk. Indeed, milk somatic cells contain lysosomes that release active proteolytic enzymes in milk, thus contributing to milk protein breakdown (Albenzio et al., 2004, 2005). Together with lysosomal enzymes, plasmin is the main native proteolytic enzyme in milk and is part of a complex protease-protease inhibitor system. Plasmin causes milk CN breakdown, thus reducing the ability of milk to be processed into cheese (Albenzio et al.,

Received June 27, 2007.

Accepted January 14, 2008.

${ }^{1}$ Corresponding author: m.caroprese@unifg.it
2005). It has been demonstrated (Politis et al. 1991; Verdi and Barbano, 1991) that milk somatic cells, and milk macrophages in particular, can convert plasminogen to plasmin, and stimulate urokinase-plasminogen activator activity in vitro. This led us to isolate macrophages from ovine milk.

Politis et al. (2002) isolated macrophages from ovine blood by using a sodium metrizoate- $5.6 \%$ polysaccharide gradient and resuspending in RPMI-1640 medium at a concentration of $1 \times 10^{7}$ cells $/ \mathrm{mL}$. Previously, macrophages from bovine milk were isolated on a sodium metrizoate-5.6\% polysaccharide density gradient (Jensen and Eberhart, 1981; Hallen Sandgren et al., 1991). Macrophages have also been isolated from bovine milk by Ficoll discontinuous density gradients (Jensen and Eberhart, 1975). There are no studies in the literature on the use of immunological techniques to isolate macrophages from ovine milk. In addition, there is a lack of available immunological kits for ovine cell separations, particularly for the different somatic cell populations of ovine milk.

The present study describes an immunomagnetic procedure for positive selection of different types of cells applied to ovine milk for the isolation of macrophages. This technique could easily be applied to study the role of macrophages in relation to 1 ) defense mechanisms of the mammary gland and 2) the release of proteolytic enzymes affecting milk quality.

Collection of bulk milk samples was carried out during early, mid, and late lactation on 5 consecutive days during 3 sampling cycles at bimonthly intervals. A total of 45 bulk milk samples were collected and analyzed for SCC with a Fossomatic 90 instrument (Foss Electric, Hillerød, Denmark) according to the International Dairy Federation (1995) standard. All milk samples were distributed into different 50-mL centrifuge tubes and then centrifuged at $2,000 \times g$ for $30 \mathrm{~min}$ at $4^{\circ} \mathrm{C}$; the fatty fraction and supernatant were removed, and each pellet was dissolved in $500 \mu \mathrm{L}$ of $\mathrm{pH} 7.4 \mathrm{PBS}+$ $0.02 \% \mathrm{NaN}_{3}$. Recovered pellets were centrifuged twice at $400 \times g$ for $15 \mathrm{~min}$ at $4^{\circ} \mathrm{C}$. Somatic cell pellets were resuspended in PBS buffer, and the SCC obtained was determined with a Fossomatic 90 instrument (Foss 
Electric) according to the International Dairy Federation (1995) standard. Milk sample preparation was standardized to obtain a final concentration of cells greater than $10^{7}$ cells $/ \mathrm{mL}$.

Separation of macrophages from milk somatic cells was performed by a magnetic positive separation (Do It Yourself, EasySep, StemCell Tecnologies, Vancouver, Canada), which is a nonspecific immunomagnetic cell selection procedure consisting of the use of antibodies and magnetic nanoparticles applied in a column-free magnetic system. In our laboratory, this aspecific kit was specifically applied for the selection of macrophages in ovine milk by using the monoclonal antibodies mouse IgG anti-ovine macrophages (MCA919, Serotec, Oxford, UK). Cells were targeted for selection by using a mix consisting of the mouse IgG anti-ovine macrophages (750 $\mu \mathrm{L}$ at a concentration of $25 \mu \mathrm{g} / \mathrm{mL}$ ), mouse $\operatorname{IgG}_{1}$ directed against dextran, rat monoclonal antibody against the $\mathrm{Fc}$ region of mouse $\mathrm{IgG}_{1}$ supplied by the kit (EasySep), and PBS (pH 7.4) $+\mathrm{NaN}_{3}(0.02 \%)$. Concentrated cells were resuspended in at least $100 \mu \mathrm{L}$ of PBS in a $12 \times 75 \mathrm{~mm}$ polystyrene tube according to their concentration. The tetrameric antibody complex was added to the cell suspension at $100 \mu \mathrm{L} / \mathrm{mL}$ cells and incubated at room temperature for $15 \mathrm{~min}$. Magnetic dextran iron nanoparticles were then added to the cell suspension at a concentration of $50 \mu \mathrm{L} / \mathrm{mL}$ and incubated at room temperature for $10 \mathrm{~min}$. Cells were resuspended in PBS (pH 7.4) $+\mathrm{NaN}_{3}(0.02 \%)$ up to a total volume of $2.5 \mathrm{~mL}$ and then mixed in the tube according to the supplier's instructions. The tube was then placed into the magnet for $10 \mathrm{~min}$ and the supernatant fraction was poured out by firmly inverting the magnet and tube. The tube was again placed into the magnet twice for $5 \mathrm{~min}$, the supernatant was eliminated, and the cells were suspended in $2 \mathrm{~mL}$ of PBS.

Several trials were performed to evaluate the purity of samples by flow cytometry; 2 different fluorochromeconjugated antibodies, mouse anti-human CD14:RPhycoerythrin (RPE) (MCA1568PE, Serotec) and $\mathrm{F}\left(\mathrm{ab}^{\prime}\right) 2$ rabbit anti-mouse IgG:RPE (STAR12A, Serotec), and 3 different labeling procedures were tested.

In the first labeling procedure, 2 aliquots of cells were labeled immediately after positive selection: a first aliquot $(100 \mu \mathrm{L})$ was added to $5 \mu \mathrm{L}$ of CD14:RPE (POST$\mathrm{CD} 14)$, and a second one was added to $25 \mu \mathrm{L}$ of $\mathrm{F}\left(\mathrm{ab}^{\prime}\right) 2$ rabbit anti-mouse IgG:RPE (diluted 1:10 in PBS; POST-RAMIgG).

In the second labeling procedure, 2 aliquots of cells were relabeled with the primary mouse anti-ovine macrophage antibody (MCA919, Serotec) after positive selection: a first aliquot $(100 \mu \mathrm{L})$ of cells was added to 10 $\mu \mathrm{L}$ of primary mouse IgG anti-ovine macrophages +25 $\mu \mathrm{L}$ of $\mathrm{F}\left(\mathrm{ab} \mathrm{b}^{\prime}\right) 2$ rabbit anti-mouse IgG:RPE (1:10 PBS;
MAC-RAMIgG), a second one ( $100 \mu \mathrm{L})$ was added to 10 $\mu \mathrm{L}$ of primary mouse anti-ovine macrophage antibody $+5 \mu \mathrm{L}$ of mouse anti-human CD14:RPE (MAC-CD14). Briefly, cells were labeled with primary antibody at room temperature for $30 \mathrm{~min}$; cells were then resuspended in $\mathrm{PBS}+\mathrm{NaN}_{3}(0.02 \%)$ to a volume of $1 \mathrm{~mL}$. The cell suspension was centrifuged at $400 \times g$ for $5 \mathrm{~min}$, the supernatant was poured off, and the cell suspension was incubated for $30 \mathrm{~min}$ at room temperature with 5 $\mu \mathrm{L}$ of CD14 in the first test tube and $25 \mu \mathrm{L}$ of $\mathrm{F}\left(\mathrm{ab}^{\prime}\right) 2$ rabbit antimouse IgG:RPE (1:10 PBS) for $30 \mathrm{~min}$ at room temperature in the second test tube. After incubation, the cells were resuspended in $\mathrm{PBS}+\mathrm{NaN}_{3}(0.02 \%)$ to a volume of $1 \mathrm{~mL}$; the cell suspension was then centrifuged at $400 \times g$ for $5 \mathrm{~min}$, the supernatant was poured off, and the pellet of cells was resuspended in $800 \mu \mathrm{L}$ of PBS.

In the third labeling procedure, the other 2 aliquots of cells were added to CD14 and fluorochrome-conjugated antibody immediately after the tetrameric antibody complex, during the cell selection procedure, to provide a strong detection signal without affecting separation performance. The $\mathrm{F}\left(\mathrm{ab}^{\prime}\right) 2$ rabbit anti-mouse IgG:RPE was added at a concentration proportional to the tetrameric antibody complex volume at room temperature for 15 min (MIX-RAMIgG). The same procedure was performed by adding $5 \mu \mathrm{L}$ of CD14 (MIX-CD14).

All these samples were acquired by flow cytometry (Coulter Epics XL-MCL, Beckman Coulter Inc., Fullerton, CA). Approximately 10,000 events were collected for each sample on a Coulter Epics XL-MCL instrument.

A morphological test was carried out by direct microscopic count in selected cell smears stained with MayGrünwald-Giemsa stain to confirm the presence of macrophages and to assess the macrophage:neutrophil ratio because of possible contamination of the neutrophils in the selected cells. Cell smears were obtained from each milk sample for a total number of 45 smears, and 300 cells from each smear were counted to assess the macrophage:neutrophil ratio.

Starting from $400 \mathrm{~mL}$ of milk, the SCC was approximately $300 \times 10^{3}$ cells $/ \mathrm{mL}$ and macrophages were below $4 \%(3.34 \% \pm 0.6)$. After the centrifugations, the enriched fraction obtained was approximately $2 \times 10^{7}$ cells $/ \mathrm{mL}$ and the macrophage count increased proportionally after positive selection. When read out at flow cytometry, the percentage of cells stained positively to mouse anti-human CD14:RPE was $99.7 \pm 0.05 \%$ (SE) in the MIX-CD14 samples, whereas in the POST-CD14 samples, the percentage of cells stained positively was 97.1 $\pm 0.06 \%$ (Figure $1 \mathrm{a}$ and $1 \mathrm{~b}$ ). Moreover, the percentage of cells stained positively to the $\mathrm{F}\left(\mathrm{ab}^{\prime}\right) 2$ rabbit anti- 
a)
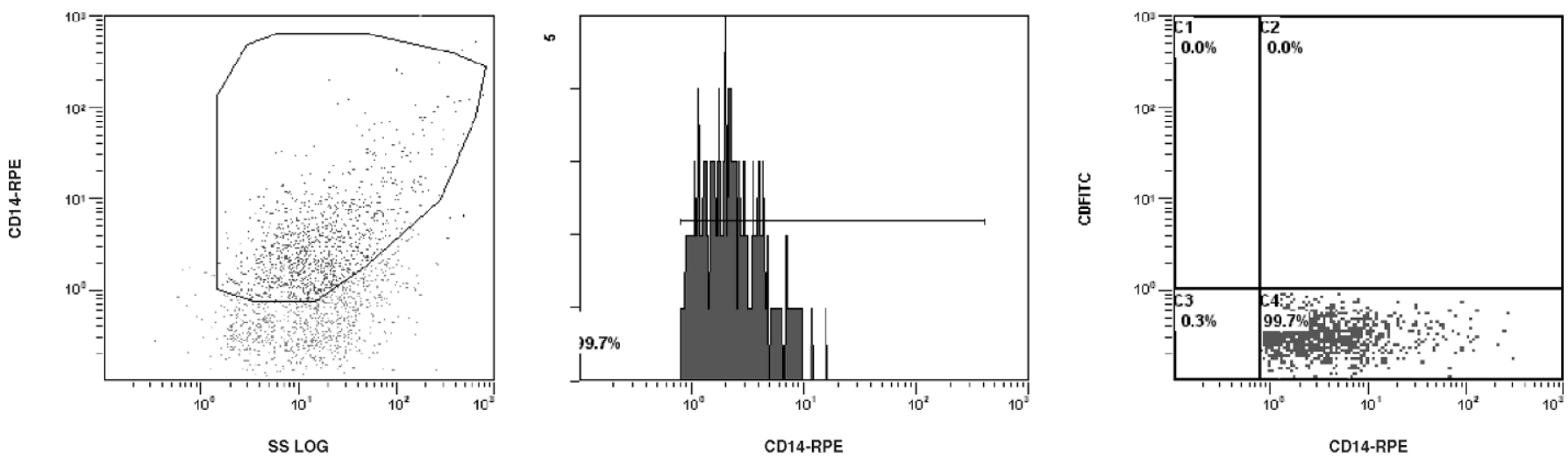

b)
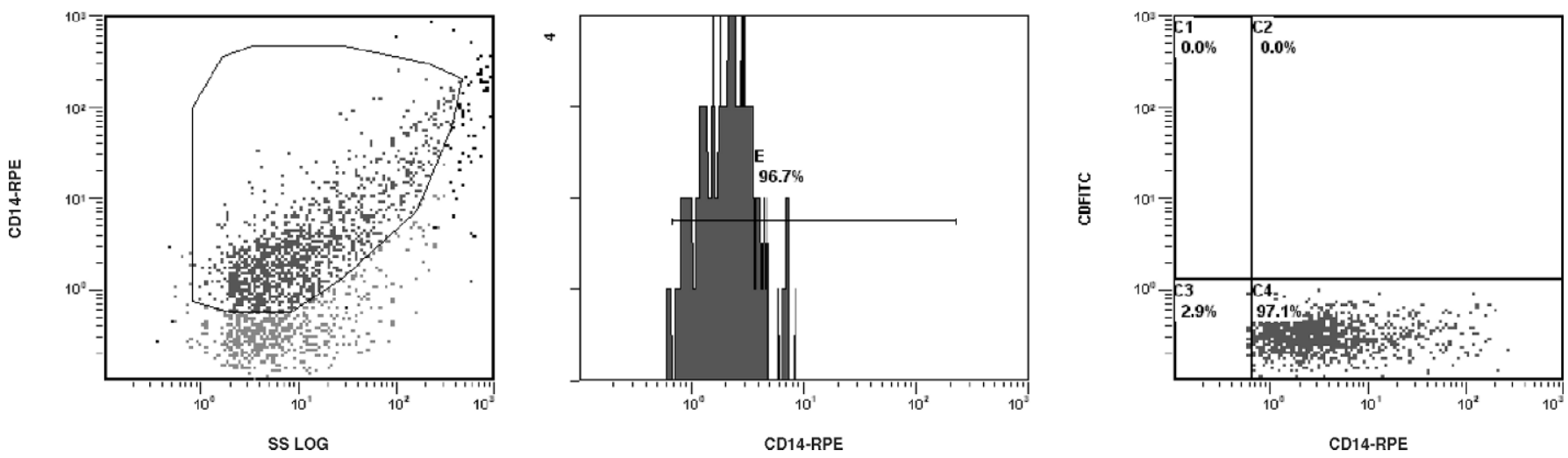

Figure 1. a) Percentage of cells stained positively to mouse anti-human CD14:R-Phycoerythrin (RPE) added immediately after the mix (MIX-CD14). b) Percentage of cells stained positively to mouse anti-human CD14:RPE added immediately after positive selection (POSTCD14). The first dot plots show the side scatter (SS) in relation to CD14; the second histograms show the fluorescence of RPE fluorochrome, and the third dot plots represent the percentage of macrophages stained with CD14:RPE.

mouse IgG:RPE added immediately after the mix (MIXRAMIgG) was $97.1 \pm 0.09 \%$, whereas in POST-RAMIgG, the percentage of cells stained positively was 98.5 $\pm 0.06 \%$ (Figure $2 \mathrm{a}$ and $2 \mathrm{~b}$ ). The 2 aliquots labeled with primary mouse anti-ovine macrophage antibody, the MAC-CD14 and MAC-RAMIgG samples, showed the same percentage, $98.5 \pm 0.07 \%$ and $98.5 \pm 0.06 \%$, respectively. Results obtained by using the 2 antibodies and 3 different labeling procedures showed that the best assessment of purity (99.7\%) among the 6 procedures was found when mouse anti-human CD14:RPE was added to cells immediately after the tetrameric antibody complex during the selection of cells (MIX-CD14).

Data from the morphological test obtained by direct microscopic count of selected cell smears confirmed the presence of macrophages (Figure 3). No neutrophils were detected.
Our application of an immunomagnetic procedure to isolate macrophages from ovine milk can be considered innovative when compared with other procedures found in the literature. The most of extensive report on macrophage physiological features deals with cells derived from laboratory animals (Wardley et al., 1976). The number of macrophages that can be collected from laboratory animals in vivo from a particular site is limited because of the relatively small size of the animal and the small quantity of macrophages obtainable from tissues (Wardley et al., 1976). Our application allows an unlimited number of macrophages to be obtained from milk of any animal species without using stimulating agents to induce an exudate with an increased number of harvested cells (Wardley et al., 1976). Little work has been done to characterize mononuclear phagocytes from species other than laboratory animals. Researchers have 
a)

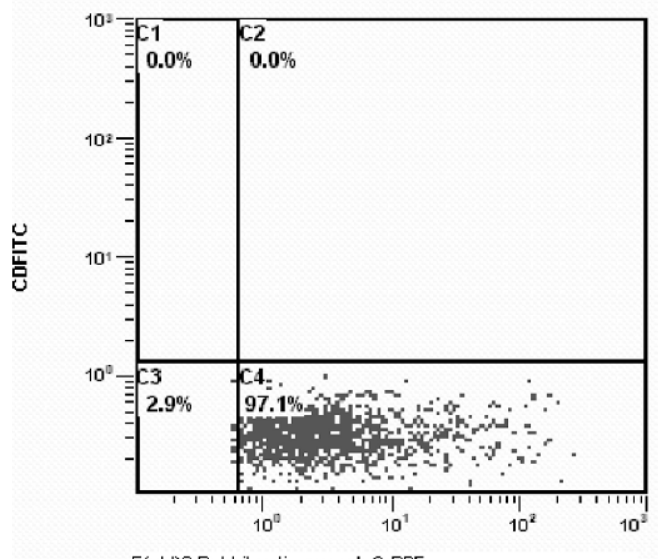

c)

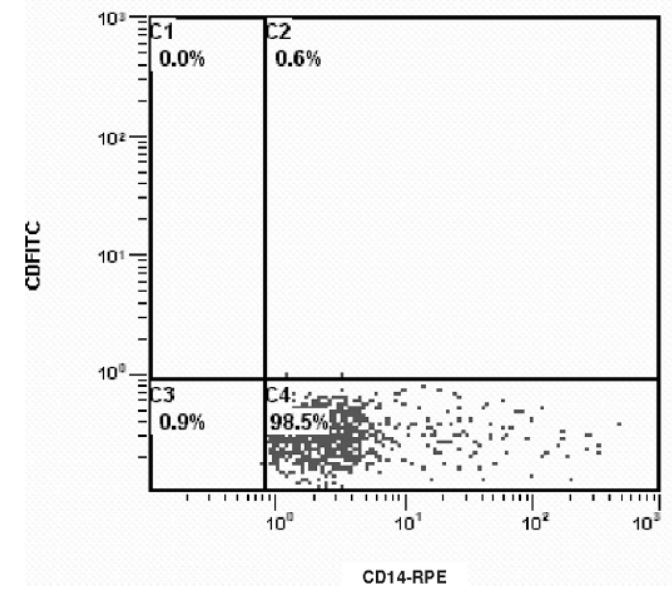

b)

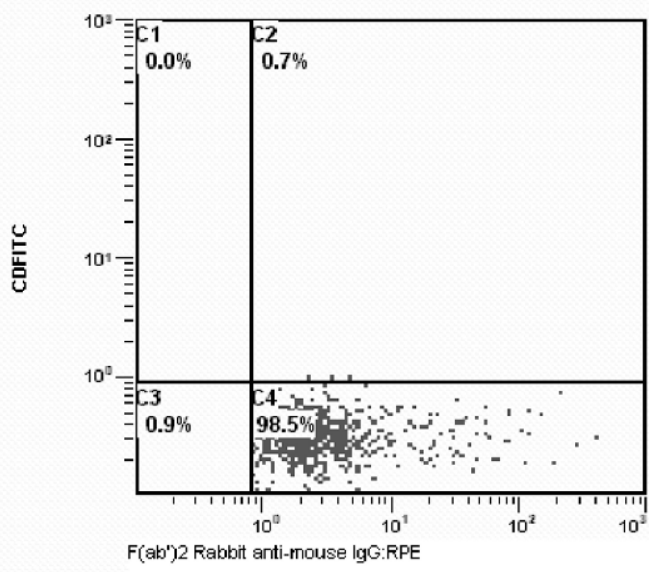

d)

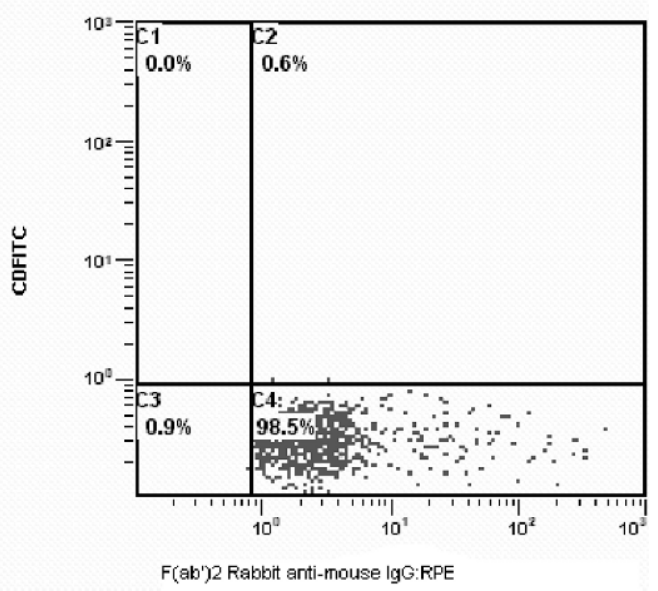

Figure 2. The 4 graphics represent dot plots of the different trials: a) the percentage of cells stained positively to $\mathrm{F}(\mathrm{ab}) 2 \mathrm{rabbit}$ antimouse IgG:R-Phycoerythrin (RPE) added immediately after the mix (MIX-RAMIgG); b) the percentage of cells stained positively to F(ab')2 rabbit anti-mouse IgG:RPE after positive selection (POST-RAMIgG); c) the percentage of cells stained positively to mouse anti-human CD14:RPE and relabeled with monoclonal primary antibody mouse-IgG (MAC-CD14); d) the percentage of cells stained positively to F(ab')2 rabbit anti-mouse IgG:RPE and relabeled with monoclonal primary antibody mouse-IgG (MAC-RAMIgG). CDFITC = IgG conjugated to fluorescein isothiocyanate.

shown that macrophages and neutrophils can be harvested from the involuted mammary gland of cows after injecting bacterial lipopolysaccharides (Wardley et al., 1976). In the same way, polymorphonuclear leukocytes have been obtained from the involuted mammary gland of sheep after stimulation with a bacterial endotoxin (Watson, 1976). Other studies have shown how to obtain macrophages from the bovine mammary gland without using a stimulating agent to define some characteristics of these cells in vitro (Desiderio and Campbell, 1980). The application of the present procedure offers the possibility of investigating a real system while avoiding false modifications that would come from external stimulation. The present immunomagnetic procedure is a reliable means of achieving a high number of macrophages while preventing the risk of contamination from other cells not under investigation. In addition, the method described in the present technical note is an innovative application for rapidly and easily obtaining a single-cell population of high purity from all the somatic cells in milk, thus allowing changes occurring in the somatic cells of the mammary gland to be monitored throughout lactation. Moreover, it allowed us to better understand the behavior of ovine milk 


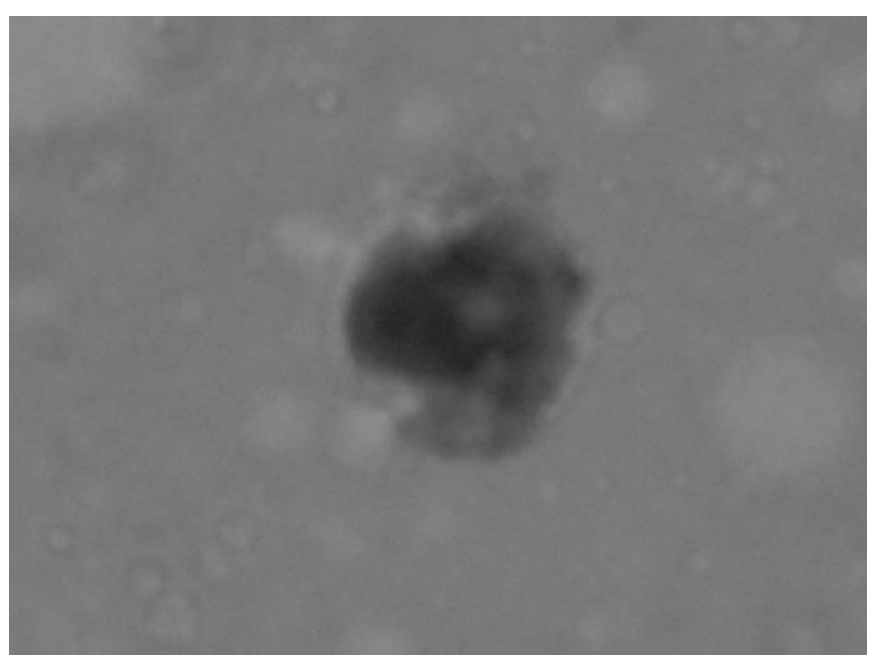

Figure 3. Photograph of a milk macrophage obtained by direct microscopic observation in selected cell smears stained with MayGrünwald-Giemsa stain.

macrophages in the plasmin-plasminogen complex, as demonstrated by Caroprese et al. (2007).

\section{REFERENCES}

Albenzio, M., M. Caroprese, A. Santillo, R. Marino, A. Muscio, and A. Sevi. 2005. Proteolytic patterns and plasmin activity in ewes' milk as affected by somatic cell count and stage of lactation. J. Dairy Res. 72:86-92.

Albenzio, M., M. Caroprese, A. Santillo, R. Marino, L. Taibi, and A. Sevi. 2004. Effect of somatic cell count and stage of lactation on the plasmin activity and cheese-making properties of ewe milk. J. Dairy Sci. 87:533-542.

Caroprese, M., A. Marzano, L. Schena, R. Marino, A. Santillo, and M. Albenzio. 2007. Contribution of milk macrophages to proteolysis and to plasmin activity in ewe bulk milk. J. Dairy Sci. 90:2767-2772.

Desiderio, J. V., and S. G. Campbell. 1980. Bovine mammary gland macrophage: Isolation, morphologic features, and cytophilic immunoglobulins. Am. J. Vet. Res. 41:1595-1599.

Hallen Sandgren, C., K. Nordling, and I. Bjork. 1991. Isolation and phagocytic proprties of neutrophilis and other phagocytes from nonmastitic bovine milk. J. Dairy Sci. 74:2965-2975.

International Dairy Federation. 1995. Standard No. 148A: Enumeration of somatic cells. Fed. Int. Laiterie-Int. Dairy Fed., Brussels, Belgium.

Jensen, D. L., and R. J. Eberhart. 1975. Macrophages in bovine milk. Am. J. Vet. Res. 36:619-624.

Jensen, D. L., and R. J. Eberhart. 1981. Total and differential cell counts in secretions of the nonlactating bovine mammary gland. Am. J. Vet. Res. 42:743-747.

Politis, I., I. Bizelis, and E. Rogdakis. 2002. The urokinase-plasminogen activator system in ovine macrophages and neutrophilis. Small Rumin. Res. 44:17-23.

Politis, I., X. Zhao, B. W. MacBride, J. Burton, and J. D. Turner. 1991. Plasminogen activator production by bovine milk macrophages and blood monocytes. Am. J. Vet. Res. 52:1208-1213.

Verdi, R. J., and D. M. Barbano. 1991. Properties of proteases from milk somatic cells and blood leukocytes. J. Dairy Sci. 74:20772081.

Wardley, R. C., B. T. Rouse, and L. A. Babuik. 1976. The mammary gland of the ox. A convenient source for the repeated collection of neutrophils and macrophages. J. Reticuloendothel. Soc. 19:29-36.

Watson, D. L. 1976. The effect of cytophilic $\mathrm{IgG}_{2}$ on phagocytosis by ovine polymorphonuclear leukocytes. Immunology 31:159-165. 